\title{
La utopía de la recuperación de Occidente
}

\author{
Josu Landa \\ Julio Quesada, Ateísmo dificil. En favor de Occidente. \\ Barcelona, Anagrama, 1994, 309 pp.
}

E

n esta obra, Julio Quesada designa como "ateísmo" a algo que, cuando menos desde Kant, es mejor conocido como "autonomía moral". En definitiva, algo que resulta bastante familiar a los interesados en temas de ética y que, por lo mismo, no necesita ser especialmente elucidado en esta recensión. Será más provechoso, en consecuencia, atender a otros aspectos del libro e incluso reducir (verbo más que problemático, cuya acción arremete contra la riqueza de un texto poblado por una vorágine de ideas, impugnaciones, provocaciones, propuestas, cantos de vida y esperanza, etcétera) el campo de observación, el horizonte de la lec. tura, a lo que a la postre aparece como su dimensión teórica central: la reivindicación de Occidente.

En realidad, más que en su título de reminiscencias decimonónicas, la clave de este último libro del filósofo español está en el subtítulo: "En favor de Occidente". Esta expresión nos sitúa inmediatamente en el centro de un debate, que se ha dado con gran intensidad entre los pensadores europeos; 10 que no ha sucedido en nuestro medio, aunque a decir verdad no han faltado colegas interesados en el tema. De modo que quien asigne un alto valor a la actualidad en un libro, aquí tiene uno que lo es como pocos, pese al tiempo transcurrido desde su publicación por Anagrama, luego de haber sido finalista en el prestigiado premio que patrocina esa editorial barcelonesa.

La noción de Occidente es el corazón y la sangre de este libro de Quesada, tanto por lo que toca a su dimensión crítica cuanto por lo que hace a sus elementos tenuemente propositivos. Ahora bien, a falta de mayores precisiones por parte del autor, es dable suponer que ha preferido proponer una idea de Occidente, primero, por la vía negativa. No se trata, por tanto, de una opción cultural y moral opuesta a lo que representa lo que muy vagamente se entiende por "Oriente". Sobre todo, no es la cuna y morada del nihilismo contra las que se ensañan con facilidad y comodidad los 
posmodernistas de toda clase. Después, Quesada ha diseminado por todas las hojas de su libro una idea de Occidente en términos más positivos; un Occidente que se nos ofrece como posibilidad revitalizadora, el rostro más poderoso, sano y vital de un programa que no se ha agotado, que de hecho nunca hemos sabido vivir en toda la intensidad que potencia. Si esta interpretación es acertada, se impone consignar un serio escollo en la propuesta central ofrecida por Quesada en su Ateísmo difícil...: si lo que cifra un porvenir mejor es lo que representa en sus raíces Occidente, ¿qué pasa con las demás posibilidades culturales?, ¿dónde queda la realidad de las diferen. cias culturales? Evidentemente, formular estas preguntas - un tanto "insidiosas", es cierto- es llamar la atención sobre un problema muy actual: el del relativismo cultural. Un problema, en definitiva, que no debe ser despachado con simples condenas a los fanatismos nacionalistas y xenófobos que, por desgracia, nos ha tocado conocer.

La reacción posmodernista ha sido lo bastante fuerte como para poner en cuestión lo que representa Occidente en el plano cultural y moral. En realidad, como lo ha visto muy bien Quesada, este fenómeno curioso e incluso interesante en la historia de las ideologías y las mentalidades ha rebasado el mero cuestionamiento y ha dado paso, por lo menos, a tres opciones igual de peligrosas: la celebración macabra de la supuesta muerte de la Modernidad occidental, la reivindicación del espíritu rebañego de que se nutren las manifestaciones más deleznables de la religión y los fundamentalismos, y la apología igualmente delirante de la razón instrumental progresista y modernista (cuyos cimientos ideológicos se resumen en el manido concepto de "neoliberalismo").

Contra estos vientos y estas mareas, Julio Quesada viene a ofrecernos otro camino. Ese camino no es el Occidente tradicional y canónico. No se trata de un retorno a la Antigüedad clásica greco-romana ni a las ideas del mundo y del hombre que brotan de la confluencia entre la cultura helenística y la tradición hebrea en el crisol del cristianismo primitivo ni, mucho menos, al momento de la institucionalización agustiniana y constantiniana de esta religión. Se trata de un Occidente repensado, rcimaginado, deslastrado de las potencialidades nihilistas que comportan los abusos de confianza en la razón y en referencias morales transmundanas, transtemporales, transhumanas. Para decirlo rápidamente, este libro de Quesada es una crítica de la Modernidad y sus excesos, sin caer en veleidades posmodernistas ni en la tentación de una ética reaccionaria.

Quesada advierte con claridad y fuerza la actual "crisis de la razón"; pero, en su caso, esta intuición no deriva en un total rechazo -por lo demás absurdo- de la racionalidad humana. Si se tratara de caracterizar, con un mínimo de fidelidad, la peculiar crítica de la razón emprendida por Quesada, habría 
que designarla como "crítica vitalista de la razón". A la aridez y frialdad de los usos nihilizantes de la razón, Julio Quesada opone una racionalidad comprometida con la vida y con un ethos a tono con ella, en su colorido, plasticidad y complejidad; también en su dimensión estética, lúdica y trágica.

No hace falta una perspicacia especial para percibir que, desde su título y sus primeras páginas, el libro de Quesada desprende un aroma utópico y moralista. Ciertamente, se trata de dos adjetivos terriblemente desprestigiados en los días que corren y el hecho de que el ensayo de Quesada no los repudie habla de la valentía desde la que ha sido concebido y tramado. Desde luego, se impone precisar el uso que se le está dando aquí a las palabras "utópico" y "moralista". En este caso, decir que el discurso de Quesada tiene un talante utópico, equivale a traer a colación la idea de utopía entendida en el sentido savateriano de un "impetu utópico"; no, desde luego, en tanto que retorno al vicio de construir con todo detalle esos "lugares que no son" y que sólo son variaciones de un mismo infierno. Por su parte, hablar del moralismo de Quesada, es tanto como referir su reivindicación de una moral autónoma y estrictamente humana (si es que, en realidad, hay alguna que no lo sea), una moral ajena a presuntas legitimaciones trascendentes, una moral del riesgo, de la heroicidad, de la afirmación de la vida en lo que tiene de alegria y sufrimiento, placer y dolor. Como se ve, algo muy ajeno a ese moralismo nihilista tan dura y atinadamente atacado por Nietzsche. En suma, eso que Quesada entiende como moral "atea"; aunque, por momentos, su discurso parece transitar por sendas más bien politeístas.

No es fácil adoptar un tono utópico, aunque sea discretamente, cuando se eleva ante nosotros el fatuo ruido de alas de la desazón y la desesperanza posmodernistas 0 nos agobia la bulla triunfalista del orden social erigido para facilitarle las cosas al capitalismo salvaje de fin de siglo y milenio. Ya se ha advertido que esto pone de relieve la valentía de Quesada. Pero, en su caso, la valentía no se da sólo como una virtud moral, sino también como una virtud intelectual. En efecto, contra la vacuidad de cierta prosa impasible hasta la indolencia, autocomplaciente, ridículamente narcisista; contra el lenguaje mercenario de los panegíricos en favor de la técnica, el dinero, el poder...; contra la pésima retórica de los nuevos medios de persuasión y disuasión, Quesada enarbola un género difícil por los dos compromisos que impone: un sentido especifico de la verdad ("la verdad que rie" y que brota del juego) y una solidaridad (por ende, una sensibilidad) humana. Ese género es el ensayo, entendido a la manera montaigneana; es decir, de un modo que prohibe la inocuidad y la fatuidad, al tiempo que exige entregarse en cuerpo y alma a un Otro que nunca falta y que no deja de reclamar una veracidad arriesgada, un espejo en que leerse sin contemplaciones. Sin embargo, es necesario precisar que, de acuerdo con Quesada, no se trata de 
reclamar una primacía incondicional del ensayo, sino de rescatar una modalidad expresiva "fronteriza", ambigua, borderline, condición que el ensayo compartiría con la novela, especialmente el Quijote y la novela negra contemporánea.

Esto último remite al tema del estilo. En el caso de Quesada el estilo no sólo es el hombre; es también el pensamiento. El estilo es la parte de energía humana más vital y cruda que sale a flote en el pozo discursivo que es el texto. Al igual que en otros puntos, en éste, el signo que caracteriza a Quesada es la autenticidad. Una postura teórica y ética determinada exige una expresión correspondiente, es decir, reclama la complicidad de la palabra, de un uso específico del lenguaje. En el libro de Quesada, el lenguaje acontece frecuentemente con la contundencia del oráculo, con la redondez de la frase lapidaria. En Ateísmo difícil..., la palabra se acerca a veces al grito, por momentos corre con la velocidad de un torrente más o menos cristalino -también más o menos turbio-, en no pocos lugares se entrega a un humor más bien contenido, así como a la ironía que no rehuye, sin embargo, la crítica ácida; en definitiva, es la misma palabra que siempre se atreve a referir lo que debe representar (como cuando se trata de plasmar, tal vez incómoda pero indefectiblemente, los mil rostros del imperativo verbo "deber"). Se trata, pues, de un estilo o un lenguaje claramente comprometido con una convicción o una serie de convicciones, lo que da al libro de Quesada una inconfundible tonalidad humana y, con ello, un atractivo mayor para el lector que busca emociones teóricas - si cabe la expresión-más fuertes.

Por su intención, tono y sentido, el libro de Quesada aspira a tener un carácter sapiencial. Para decirlo de otro modo, es un libro en el que lo estric. tamente teórico está al servicio de intereses prácticos, éticos. Sin embargo, aquí es donde toma relieve por lo menos una debilidad de Ateísmo difícil...: la incompatibilidad entre la sabiduria que quisiera propugnar, por una parte, y la amplísima, inconmensurable erudición que alberga el libro, por la otra. Ya desde Heráclito sabemos bien que la polimatía y el pensar no se llevan. El hecho de que Quesada recurra a veces insistentemente a toda una galería de filósofos y escritores, en la que figuran desde el gran pensador efesio hasta Ortega y Gasset, pasando muy privilegiadamente por Nietzsche, así como por Rilke, Cervantes y Kundera, no garantiza una mayor solidez ni un verdadero sustento a lo que en definitiva debe interesar, que es el pensamiento del propio Quesada. Una de las trampas del ensayo, como género, es precisamente la tentación de la erudición desbordada. Desde luego, el libro de Quesada encierra un loable esfuerzo hermenéutico, por momentos no sólo audaz, sino brillante. No obstante, da la impresión de que a veces esa audacia interpretativa cede demasiado a ciertos destellos más propios de un polígrafo, a costa de sacrificar el programa sapiencial al que deberían incardinarse. Por 
lo demás, la efectividad de un mensaje sapiencial es directamente proporcional a la claridad y hasta a la desnudez del estilo en que se presente. En el fondo, se trata de exigir alguna orientación para atender justamente a lo que de "dificil" comporta, en el plano ético, el ateísmo sui generis que propugna Quesada.

No cuesta mucho sospechar que al autor de Las cenizas de Heidegger-El legado de Hölderlin y de Un pensamiento intempestivo. Ontología, pensamiento y politica en Nietzsche, o sea a Quesada, no le ha durado mucho el gozo de prodigar el programa de sabiduría que básicamente contiene el texto que comentamos. Con Ateísmo difícil..., Quesada puede haber alcanzado una meta importante, pero todavía insuficiente: alborotar a ciertas zonas del hormiguero intelectual de fin de siglo y milenio, sin que por ello logre proponer una opción que de veras logre contrarrestar los efectos de tanta algarabía, tanta confusión, tanta oscuridad, tanta mala escolástica, incluso tanto nuevo catecismo. En verdad, no es poco lo que debe reconocérsele a los afanes de Quesada, pero éstos están muy lejos de fructificar en una propuesta de formas apropiadas de vida - en suma, una sabiduría - con una fundamentación aceptable. En el juego serio que también es la filosofía, cada jugada, cada baza, debe sustentarse en las razones del caso. De otra manera, se corre el riesgo de incursionar en el terreno pantanoso de la simple proferencia oracular o del decreto genial o de los conatos esteticistas. Desde luego, no se trataria forzosamente de una fundamentación convencional. Al contrario, tal vez sea cosa de explorar nuevas vías de verdadera fundamentación, más allá de las afirmaciones impactantes, las exégesis llamativas y otros artilugios eficaces para remover ciertas conciencias especialmente sensibles y abiertas, pero para poco más. Una nueva forma de fundamentación que, en último término, deberá ser ética o de profundas implicaciones éticas. Quesada puede y debe avanzar firmemente en esta dirección. Es razonable esperar un nuevo libro en el que asuma ese reto. Mientras eso sucede, desde luego, sólo queda celebrar y recomendar altamente la lectura de este libro, en el que el lector encontrará un discurso sugerente y de una saludable tonalidad crítica sobre temas fundamentales como el tiempo, la muerte, la verdad, la democracia y muchos más, tratados desde el interés de redimensionar el proyecto cultural que todavía puede representar Occidente. 